\title{
INTERNALIZATION OF MULTIPLE PERSPECTIVES OR DISSONANCE REDUCTION?
}

\author{
Robert A. Wicklund and Jack W. Brehm \\ University of Trieste \& University of Kansas
}

running head: Multiple perspectives or dissonance?

We are indebted to the following for their expert advice and criticism of an earlier version of this manuscript: C. Daniel Batson, Guido Gendolla, Eddie Harmon-Jones, Giuseppe Pantaleo, Peter Schönbach, and Paul Silvia, and we are indebted to the Alexander von Humboldt Foundation for support in the form of a Senior Research Award to the second author.

Mailing address: Jack W. Brehm

Department of Psychology

1415 Jayhawk Blvd.

University of Kansas

Lawrence, Kansas 66045-7556

E-Mail: jwbrehm@ukans.edu

[12/2001; 31/5/2002; 17/01/2003] 


\begin{abstract}
In numerous research programs based on the concept of cognitive dissonance, participants play a role that is ostensibly in conflict with their preexisting values. A strict reading of dissonance theory (Festinger, 1957) leads us to suppose that these role-playing, or "forced compliance" procedures generally create results that are not implied by the theory. Two alternative interpretations of the forced compliance phenomena are introduced here.

The first of these regards the procedures from the standpoint of internalization of multiple value repertoires. From this viewpoint, the effects of roleplaying do not stem from contradictions-or dissonance-within the person's sets of values. The second interpretation, based in part on Festinger's theory of efference, allows that the effects of role-playing derive from the guiding character of intended action.
\end{abstract}




\section{INTERNALIZATION OF MULTIPLE PERSPECTIVES OR DISSONANCE REDUCTION?}

Robert A. Wicklund and Jack W. Brehm

In literally hundreds of experiments, people who have been induced to "freely" choose to say or do something with which they originally strongly disagreed, subsequently indicate they hold a more moderate position. Dissonance theory (Festinger, 1957), on which most such experimental work has been based, stipulates that how a person resolves the disagreement between prior attitude and current behavior depends on the resistance to change of relevant cognitions. Thus, when people say something in disagreement with a prior attitude, they should bolster one side of the issue and trivialize the other-that is, they should adopt a strong position either favoring their recent behavior or favoring their prior attitude, depending on which cognitions are more resistant to change. A moderate position does neither, but a moderate position is what "forced compliance" experiments produce.

Sally is a college student in the USA, has grown up in the American south, the daughter of an entrepreneurial family. Her junior year in college is approaching, and after contemplating several possibilities for a year abroad, she elects to spend her time in France. Her first several weeks with her host family, in a small city, entail a novel living context. She models and imitates the language and makes purchases in keeping with modern French styles. She also adopts a more traditional French pattern of eating, in that she sits 
together with the family for meals, and does not "graze" or nibble, or eat on the street, as was her custom back home (Stearns, 1997).

The father of the French household, a union leader, guides Sally toward opportunities to play the role of the French labor force. Not only does she begin to try out the vocabulary corresponding to labor rights, but she also takes a part-time job and finds herself in the midst of a work force that is not reluctant to strike.

\section{Internalization of a New Perspective}

The classic and modern literature on internalization (Abelson, 1986; Berger \& Luckmann, 1966; Charon, 1979; Deci, 1975; Kelman, 1953; King \& Janis, 1956; Habermas, 1996; Hoffmann, 1977; Mead, 1934; Wicklund, 1989) can readily be brought to bear on the dynamics of Sally's value systems. Central in these conceptual approaches is activity, meaning that an attitude, value, moral, personality trait, or attachment to a material possession is internalized not through passive exposure, but by the person's becoming active with respect to the object--i.e. contents--of internalization.

This means concretely that the behavioral disposition (attitude; value; moral) or material possession comes to be owned subjectively, not through passive exposure, but by the person's becoming active with respect to the new perspective or possession. A sense of free will, volition, and lack of constraint underlies the acquisition of a subjective attachment to,or ownership of, the aspect to be internalized. Thus relatively unconstrained role-playing, improvising on the basis of a culturally-set pattern, choosing or altering the 
contours of one's possessions (Habermas, 1996), and otherwise acting in unconstrained ways can lead to internalization. It follows, of course, that a lengthy or effort-ridden route to internalization will firm up one's sense of acting volitionally, and reduce any sense that the value or possession, so acquired, has been handed out or forced on oneself.

In the case of Sally abroad, this would mean that her French family has posed numerous models for action, has not placed heavy constraints on her or shaped up her behavior strictly with incentives and threats. A new value acquired under such circumstances is then likely to be regarded as "her own" (Hoffman, 1977; Wicklund, 1989), and material possessions, such as French clothing or books, are also more likely to be regarded as her own, thus as closely attached to her own person, and as attractive (Habermas, 1996).

Under these circumstances Sally is not simply the passive recipient of information, learning about a culture in a trouble-free manner. To the contrary: All that she undertakes in the sense of her role in labor relations, new culinary habits, the language, and other daily affairs is accompanied in the initial stages by a variety of emotional states. These will be variously experienced as frustration (Amsel, 1972), conflict, surprise, embarrassment -as she is in the course of trying out a multitude of unfamiliar behavioral perspectives. Active improvisation and attempted role-playing are frought with awkwardness, starts and stops; delay of gratification is an integral component of acquiring complex new habits and orientations (Mischel, 1996). 
To be sure, Hoffman (1977) even refers to "optimal levels of arousal" as furthering the internalization of moral values.

The fact of difficulties, frustration, and accompanying emotions has one general meaning for any of the preceding perspectives on internalization: The more barriers to proceeding in a given new direction, no matter whether the barriers are based in physical, temporal, or internal (e.g. competence) factors, the greater should be the sense of being internally directed (de Charms, 1968), and the more the person should be motivationally aroused (Brehm \& Self, 1989; Brehm, Wright, Solomon, Silka, and Greenberg, 1983; Wright, 1996). Of course, it functions this way only so long as the person does not abandon the effort and retreat from the novel opportunities for internalization. It is this sense of action stemming from a "causal agent self" -- the feeling of being an origin -- that is the common denominator of all of the above notions about internalization.

As the weeks pass, Sally should progressively gain a subjective feeling of owning much of what she has freely and diligently practiced (Abelson, 1986; Habermas, 1996; Wicklund, 1989). More concretely, the child developmental and other literature on internalization points to the following when it speaks of a value, or some socially esteemed object, as having been internalized:

1. a sense that the contents are "mine",

2. the internalized condition will serve as a basis for future behavior, thus moral action, or protection of possessions, 
3. the person will project the ownership backward in time, coming to believe that the ownership is a long-term affair (Wicklund, 1989),

4. a heightened valuation of the contents of the internalization (Habermas, 1996). Certainly this latter point is quite evident as a derivation from Heider's (1958) ideas about the relation between unit formation and affect.

This means that Sally will gradually come to think of certain pro-labor values, as well as French eating habits, as "her own". Second, she will come to execute behaviors in line with these new values without constant prodding from the social environment. Third, she will regard her values and possessions, so acquired, as having been in her repertoire for a considerable length of time, even prior to her recent French experiences (Wicklund, Reuter, \& Schiffmann, 1988). Fourth, this internalization will be accompanied by her attraction to these hard-earned aspects of her new existence.

\section{Multi-Faceted Repertoires}

In a similar manner Sally, in her younger years, had internalized a variety of corresponding values, styles, linguistic habits and also attachments to material possessions. Many of these, such as her family's low esteem of workers' rights, were brought into her personal grasp in the same way as her French values. That is, role-playing, and not simply passive exposure, accompanied the internalization of the repertoire that she had gained in her local American community. 
These new and old systems can exist side-by-side, and they do not necessarily have to be in psychological conflict with one another. If we follow the reasoning of Baldwin and Holmes, 1987; Berger and Luckman, 1966; Charon, 1979; Flanagan, 1996; Kvale, 1996; Gergen, 1991; and Wicklund, 1999, the elements that are internalized later do not cancel out or replace those internalized earlier. Rather, Sally's progressively encompassing the elements of pro-labor in France, as well as many other new behavioral dispositions, can be called expanding her internalization repertoire. There is no theoretical language in the internalization literature to suggest a limit on the breadth of one's repertoire. The literature implies neither a limit based on capacity nor one based on contradictions or illogic. Thus the feeling or emotion of ownership pertains simply to ownership, to what is "internal", and does not automatically include an impulse or need to substitute the new for the previous values or morals.

Within this context of actively internalizing behavioral perspectives and coming to sense ownership, there are underlying reasons for supposing that the new and the old can exist side-by-side:

1. Security. The person whose values, skills, or other possessions are anchored in long experience or training might be said to be "secure", a notion that surfaces in a variety of psychological literature (Horney, 1950; Rosenberg, 1979; Wicklund \& Gollwitzer, 1982). It follows that such behavior/experience-based security allows the person to explore, to try different routes, to engage in actions that for the observer seem to contradict 
or disparage the originally-internalized direction. Insecurity, in contrast, would set a limit on the readiness to expand one's repertoire.

2. Ownership takes precedence over consistency. Diverse sources of literature point to the idea that ownership/internalization reduces or circumvents the person's consideration of the "fit", or perceived consistency/inconsistency, among the facets that have been or are being internalized.

For one: Ainslie (1986) begins with a person who has adopted a relatively long-term project, such as weight-reduction. But then come freelyinstigated deviations from the long-range project, as when the individual -failing to tolerate the frustration -- elects to imbibe in chocolate and heavy fried food. In those moments, according to Ainslie, there is no psychologically felt contradiction or discrepancy. All of the projects or perspectives belong in the person's active set of behavioral dispositions.

Second, a set of notions by Flanagan (1996) also begins with the active individual, the activity leading to what the author terms "personal identity". The activity, for Flanagan, does not produce an identity with a singular direction or unitary set of values, but rather, the product is a "multiplex self" (p. 67), meaning behavioral dispositions that are not coherent with one another for the observer.

Also pertinent are the derivations from Meadian (1934) theory such as Charon's (1979) statement. Again we have an activity/imitation-based internalization of values, with a highly diverse, heterogeneous result. This 
viewpoint does not assume a need for complete congruency among the values ("generalized others") that are so internalized. Symbolic interactionism is also the starting point for the empirical work of Baldwin and Holmes (1987), a project that illustrates experimentally the heterogeneity of the individuals' values.

Finally, it is interesting to examine how people treat the personality traits that are typically associated with their own areas of expertise. Several studies by Wicklund and Braun (1990) and Wicklund and Koller (1991) show that respondents whose competencies are firmly anchored in experience or training are not intent on creating an internally-consistent personality portrait for that competence area.

Taken together, these several pertinent directions imply that Sally and her counterparts will not be attuned to incongruities among the various, mutually relevant facets that have been or are being internalized. Tolerance in matters of sexually explicit literature does not interfere with possessing Puritanical values (Baldwin \& Holmes, 1987); having a Personality Trait A does not preclude a sense of also possessing an opposite Trait B (Sande, Goethals, \& Radloff, 1988). Ownership, as resulting from the person's own efforts, evidently suppresses or renders irrelevant the urge to create a good Gestalt or internal logic among the features that belong to one's own repertoire.

Confrontation of the Two Values 
In the midst of the junior year abroad Sally's father shows up for a brief visit. He brings with him the salience of a number of values that Sally had earlier incorporated, including the notion that labor should be used expediently. We may focus here on these two seemingly opposing value systems -- protective of labor in France vs. using labor expediently in Sally's birth place -- in order to illustrate the perspective of the theory of cognitive dissonance on the situation.

First of all, cognitive dissonance theory (Festinger, 1957) would regard the two values as relevant for one another in Sally's perceptions. They are both approaches to labor relations, and her father's presence makes the juxtaposition compelling. The two values are also ostensibly in dissonant relation: One implies the negation of the other. To be sure, the process of Sally's role-playing and practicing pro-French values regarding labor, against the backdrop of her earlier persuasions, is akin to the procedures followed in hundreds of pieces of research oriented around dissonance theory. The Cognitive Dissonance Perspective on Sally's State

A traditional cognitive dissonance analysis must regard the values, sentiments, and behavioral tendencies experienced by the protagonist. In this case these elements (called "cognitions" within the context of the theory) are the ones pertinent to the non-fit between Sally's two stances regarding labor. For example, Sally has a certain built-in social support for her American-styled view, particularly in the form of her father's presence. She may also imagine working in her father's firm after college, all of this being 
congruent (consonant) with the value internalized earlier. As for the recentlyinternalized French values, she has the social support of her French family, co-workers, and also knows that she enjoys her workplace in France. Thus, in adding up all of the cognitive elements that are potentially dissonant or consonant with one another, we arrive at a formula that is determined by the number of them, but also weighted by their importance (Brehm \& Cohen, 1962; Festinger, 1957; Harmon-Jones \& Mills, 1999; Wicklund \& Brehm, 1976).

Sensing these discrepancies, and presumably motivated to do something about the dissonance brought forth through the simultaneous existence of all of the discrepant elements, Sally will set on a course that involves adding more consonance to one side of the cognitive clash, while subtracting elements from the other side. That is, she will effect dissonance reduction in a manner oriented around one of the two sides that are in non-fit. From that point on, all cognitions that support the "favorable" side are labeled by the theory as consonant, while those supporting the "unfavorable" side are labeled as dissonant.

If the precedent established by Festinger's forced compliance paradigm is taken as a guide line, empirical research has Sally bolstering the side associated with the more recent commitment. The French labor values and all cognitions in accord with that direction will be emphasized, will gain in importance, and she will expose herself selectively to information favoring the French value. The cognitions that now qualify as "dissonant", meaning the 
values stemming from the American family, will be eliminated and/or trivialized.

But is it plausible to assume that the recently acquired values of her French experience are more ingrained, more resistant to change, than those from her previous 20 years of living at home? Is it plausible to assume she can so easily rid herself of the values instilled by her parents and similar others? [This, then, is the first problem: delete??] The forced compliance paradigm would have us believe that the cognitions derived from one's history are easier to change than the cognitions typically created within the last 20 minutes in the laboratory.

\section{Resistance to Change}

The concept of resistance to change is what sets the theory apart from other notions about cognitive conflict or imbalance, and has been regarded as the aspect of the theory that gives it a unique predictive power. This is the construct that provides the answer to "What direction?" in regard to reducing dissonance, thus points the researcher or practitioner toward the end state of affairs that the person experiencing dissonance will seek.

Little systematic work has been done to clarify or operationalize the notion of resistance. In the original statements by Festinger (1954/1999; 1957), there is the sense that resistance is bound up with notions of human motivation, behavior, and external physical reality. For example, in the earliest statement (1954/1999), the resistance of a given cognitive element was regarded as a function of the resistance to change of the behavior(s) 
underlying that cognition. In turn, the resistance to change of the behaviors depended on the intensity of motivations addressed by those behaviors ( $p p$. 362-363, Festinger, in Harmon-Jones \& Mills, 1999).

Resistance to change was dealt with similarly in the first formal writing on the theory (1957), in the sense that resistance of cognitions stems from the relative fixedness of behaviors pertinent to the cognitions. In addition, Festinger named the forces of external reality (e.g., it is difficult to deny the fact of a rain storm) as well as the inclusion of a cognition in a tight network of other cognitions (p. 27). The sum of these three sources of resistance to change -- the behavioral, the constraints of a fixed environment, and the cognitive imbedment of the relevant cognitions --constituted the conceptual basis for dissonance researchers' use of the resistance concept.

But as the theory came to be anchored in empirical research, the formal use of resistance to change as a device for deriving precise predictions was by and large dropped. Notable in this respect is the forced compliance paradigm, whose flagship in the literature has been the Festinger and Carlsmith (1959) experiment. The theoretical parts of the article as well as the statements of prediction make no mention of resistance to change. Perhaps the investigators thought it obvious that the participants' cognition about own behavior would be more resistant to change than the cognition about the enjoyableness of the tasks, for which there was a very brief history. In discussing the forced compliance issues conceptually, Festinger (1957) also leaves out the resistance-to-change concept entirely, and simply allows 
that dissonance reduction in the form of opinion change will be toward favoring the most recently enacted, opinion-relevant behavior.

The commitment to recent action was given an expanded role in the 1962 version of cognitive dissonance theory by Brehm and Cohen, and in turn set the stage for further experimental research on the theory. From that point on there was virtually no questioning of the idea that dissonance reduction would generally be oriented around the recent commitment. Brehm and Cohen also discussed contrary cases at some length (pp. 55-60), under the rubric "boomerang effects". This latter conceptual aspect, having to do with whether the previously-existing value/opinion might be more resistant to change, has not been followed up systematically in subsequent tests of the theory. Cases of a predicted boomerang effect, following 1962, are rare.

The issue of "Which cognition is more resistant?" was discussed again by Wicklund and Brehm in 1976:

It may be naive to say that one cognition (recent behavior) is firmly rooted in behavior, while the other (prior attitude) is not. If for example the attitude is a political belief, there is every likelihood that some sort of belief-consistent action has been taken previously... This being the case, are we not dealing with two opposing cognitions that should both be highly resistant to change? And if so, which cognition is the stronger? Around which cognition will dissonance be reduced? (p. 6). 
Noting that the empirical work underlying the theory generally manifests attitude change in the direction of the recent commitment, we pointed out that an extra-theoretical assumption must be made in order to account for the apparent uniformity of the attitude change effects. More concretely, two extra-theoretical reasons were offered in an attempt to give some interpretation of the accumulated forced-compliance effects:

1. Taking an overt position at variance with an earlier one is a form of conversion. It may generally be true that a conversion is difficult to reconvert. There are barriers of having to admit to hypocrisy, indecisiveness, and uncertainty; and

2. The recent behavior is bound to be more salient in the individual's consciousness. If previous behaviors are relatively out of mind, they provide less basis for a highly resistant-to-change cognitive element (p.6).

These two supplementary assumptions were not followed up in a critical manner, but if we examine the research to date that is relevant to them, they hardly hold water. Regarding the first assumption, research participants are in any case admitting to hypocrisies implicitly: Their final opinion positions usually continue to favor the original position -- that is, the side of the issue in opposition to the role-playing. And given that their final opinions tend to be nearer the neutral-point than their original opinion, participants are apparently less sure of their original stand, but not converted to the role-played stand. 
With respect to the second assumption, there is now a considerable body of experiments that convincingly makes subjects' original position highly salient (Brock, 1962; Green, 1974; Pallak, Sogin, \& Cook, 1974; Ross \& Schulman, 1973; Zanna, Lepper, \& Abelson, 1973). Attitude change in the direction of the recent commitment continues anyway, and uniformly, as long as subjects have a semblance of free choice in their various role-playings.

These consistent findings clearly disagree with what the 1957 dissonance theory lead one to expect. Sally's long history of behaving in the tradition of her family, and of being surrounded by undeniable environmental factors congruent with that value imply that her earlier-established value will be more resistant. By this logic, Sally's dissonance, if she does indeed experience the state as described theoretically, should entail bolstering the earlier-formed value and abandoning or trivializing the recent one (see Brehm \& Cohen, p. 59)

Do the Effects Then Indicate "Closing Down"?

Dissonance reduction should result in a strong and relatively uniform set of cognitions favoring one side and derogating the opposing side. But as we have noted, post-role-playing attitudes appear to be more moderate, not more polarized. Dissonance theory fails not only in predicting which side will be strongly endorsed, but also in predicting that the final result should be a one-sided attitude. Is there, then, a possible alternative way to understand the attitude results of forced compliance research? 
Referring back to the notions of internalization, we can say that these same kinds of circumstances, i.e., relatively free-willed, non-forced, frustrating and cumbersome role-playing and the like, should lead to multiple perspectives. This means that the older set of values and the newer set exist side-by-side, whereby either set can be implemented. The foregoing internalization-theory use of such role-playing situations assumes a progressive opening-up, a quantitative enlargement and heterogeneity within the person's behavioral dispositions.

The shifts in attraction to role-played positions are clearly a reflection of the taking-ownership phenomenon (Habermas, 1996). Had the Festingertradition studies also measured the subjective feeling of ownership, the sense of possessing the value a long time, or the readiness to implement the new value in behavior, the picture would have been more complete. Important for the multiple-internalization idea is that the "resting state" of respondents' cognitive systems, i.e., the attitude as reflected in the post-measure, does not bring us to conclude that anything has been excluded from the broader value repertoire. Generally the previous value carries more positive affect than the more recent one, and there is no evidence that subjects' subsequent behavioral inclinations are aligned solely with the new direction. In sum, we find no clear evidence for closing down.

Procedures that Should Minimize Dissonance

Certain experimental results associated with the dissonance school confront people, against their will, with a new or foreign value (Götz- 
Marchand, Götz, \& Irle, 1974). By the usual way of doing things, such a procedure should not create cognitive dissonance, because the volition element is missing entirely. Interestingly, these procedures seem to result in a re-affirmation of the earlier position. Rather than adopting that which is new, or recent, subjects can be shown to retreat. Such an effect is indeed in line with the resistance-to-change reasoning.

But such findings do little to make the case for dissonance theory as it is usually stated, i.e., as a theory of volitionally-mediated cognitive discrepancies. Moreover, this kind of finding has no singular qualities that would separate it from other bodies of research on ego-protection or defensiveness (Shaver, 1975; Snyder, Stephan, \& Rosenfield, 1978;Wicklund \& Gollwitzer,1982).

For these reasons it is doubtful that such procedures, which essentially attack values or competencies, indicate a direction that is desired in trying to clarify the character of cognitive dissonance processes. And this kind of dilemma raises the more general question of whether a cognitive closing down--an attempted narrowing--is part and parcel of role-playing procedures at all.

In Search of a Process of Closing Down: What Criteria?

A Need for Coherent Action? One can underpin a presumed tendency toward closing down with the assumption that a straightening out of cognitive elements serves the organism's long-term survival (Festinger, 1954/1999, p. 356) or the desire for efficient action (Harmon-Jones, 2000). Taking the 
argument to Sally's case, a shift in favor of French values and a minimization/derogation of the USA-values would be adaptive in her future France-based activities. The difficulty in bringing this assumption to the roleplaying case is that participants' final values continue to be in accord with the original values; there is no conversion. Further, those same people seldom proceed to take subsequent actions congruent with their role-played positions.

More articulated indices of attitude change. Articulated measures, in the sense of separate measurements for the chosen and rejected alternatives, are common within the literature on free choice (see Brehm \& Cohen, 1962; Wicklund \& Brehm, 1976). This means that if a person selects one of several available occupations, sports activities, or consumer articles, it is possible to see whether the effects are limited to heightened evaluations of the selection, or to the derogation or refutation of the rejected alternatives.

Such articulation as applied to Sally's American and French values simply means separate indices for each of the two cultural orientations. A strict dissonance derivation would assume an increment in pro-French leanings along with a derogation of American labor values.

One approach to more differentiated measurement, with a concentration on the possibility that openness to both positions on an issue is possible, has been initiated by Pantaleo (1999; 2001). For instance, Pantaleo (2001) reports a study in which non-smokers were recruited for a characteristic forced-compliance cognitive dissonance experiment. Subjects assigned to a 
control condition were asked to write a short essay on the topic of advertising in television, i.e., an essay irrelevant to smoking, while those in the experimental condition were asked to compose an essay favoring the prosmoking position. Both groups were given the impression they had high choice about compliance in writing the essay.

After the essay all subjects read brief statements supposedly from two individuals -- one in favor of smoking, the other against. The dependent measure asked each participant to indicate which one of the following three statements he most agreed with:

1. I am primarily in accord with the argumentation favoring smoking.

2. I am primarily in accord with the argumentation against smoking.

3. I find that both of the argumentations are plausible.

The clear majority of those in the control condition (79\%) endorsed the statement against smoking, while the endorsement by those who wrote in favor of smoking was split (50/50) between the anti-smoking statement and the statement finding both arguments plausible. In short, in Pantaleo's use of more articulated measures, the effects appear contrary to a closing down phenomenon.

Trying indices other than value change. Occasionally the cognitive dissonance literature has employed indices of affective states (e.g., Elliot \& Devine, 1994; Shaffer \& Hendrick, 1974; Cooper, Zanna ) as well as measures of physiological arousal (e.g., Harmon-Jones, 2000). The idea is that cognitive inconsistency should be reflected in tension and discomfort. 
But the interpretive problem remains: Tension and arousal are a part of the conflict and difficulty associated with internalization and subsequent enrichened value repertoires.

\section{Opening vs. Closing: Summary}

To be sure, there are manifold effects of a person's more-or-less voluntarily trying out a new opinion/value position. But the procedure per se, no matter whether labeled role-playing, drama therapy, forced-compliance, 'induced' compliance, guided imitation, or the like, cannot be equated with one specified psychological process. As we have shown, there is no firm basis for concluding that such procedures as guided imitation or the roleplaying of a new position automatically brings forth a dissonance reduction effect that is guided by a resistance-to-change principle.

To call such procedures "forced compliance dissonance paradigms" closes one's interpretive possibilities. This is particularly consequential in the present case, because the same kinds of procedures have typically stood for the every-day course of events in young persons' acquiring a diverse repertoire of value systems. In addition, one must come to grips with the observation that adults often embody multiple sets of leanings--behavioral dispositions (Sande et al, 1988), values (Baldwin \& Holmes, 1987), attitudes (Pantaleo, 1999; 2001) -- that seem to contradict one another.

There are indeed processes of narrowing or closing down that follow the theoretical guide set up by the original cognitive dissonance theory, but these predicted effects are to be found primarily within the free choice 
paradigms, i.e., those in which no one exerts pressure to adopt an untried or foreign direction. As we have tried to show, the role-playing procedures do not result in closing-down effects that are in clear accord with the resistanceto-change element that is so central to dissonance theory. To the contrary, there is just as much reason to suppose that role-playing or guided imitation leads to an expanded repertoire -- to multiple internalizations.

The unequivocal closing-down appears most readily when a new position or point of view is forced on the person. In these cases, as in producing defensiveness by attacking or confronting an individual's prior convictions, the person's retreating to one narrowed position or belief is evident enough. Cognitive dissonance theory's difficulty in such settings is that force, or surprise, have historically been regarded as weakening or eliminating dissonance, and therefore undermining the closing-down course of events.

The Role of Recent Behavior: Efference

Behavioral intentions and efference. Any theory about decisions must assume a strong relationship between perceived qualities of choice alternatives and decisions. Obviously, if there is no relationship, the organism will perish except when surrounded by favorable outcomes. Furthermore, the better the discernment of quality in alternatives, the stronger can be a person's efficiency in action and consequent quality of life. But making use of available discernment depends on a close relationship between perception and judgment, on the one hand, and decisions to act, on the other. 
For a person to maximize surviving and thriving, the sole determinant of such decisions should be perceptual and judgmental accuracy concerning the "true" qualities of alternatives.

This surely is what Festinger assumed about predecisional processes, and it may also be why Festinger's initial analysis of cognitive dissonance (Appendix A, pp. 355-379, Harmon-Jones \& Mills, 1999) was in terms of behavior, on the one hand, and cognition about the environment and self on the other, rather than just in terms of cognition of any kind. The published formulation of dissonance theory treats a person's taking action as just one more source of cognition, along with other information about the self and the environment. Although this approach seems elegant conceptually, which may be why Festinger chose it, the role of action in determining dissonance and dissonance reduction was thereby diminished. As we have explained above, the theory, if interpreted strictly, does not work properly. Beliefs, attitudes, and values long held and practiced do not appear to be the cognitions around which dissonance from compliant behavior is reduced. As most dissonance researchers have assumed, and as Beauvois and Joule (1996) made explicit, the compliant freely chosen behavior appears to have superordinate status among cognitions. This means that the more elegant theoretical formulation (Festinger, 1957), which demoted behavior to knowledge similar to all other knowledge, may have been in error.

Following this line of thought, another way to interpret forced compliance effects, as well as those of free choice studies, is that recent 
behavior is the criterion by which all relevant cognition must be judged. Prior to behavioral commitment, a person's task is to produce behavior that is maximally consonant with what is known about the self and the environment. After the commitment, when rationality has done its bit, there is a tendency to see the world in accordance with the commitment. While there are constraints on cognitive changes regarding the chosen course of action, given that effective behavior must still be guided by reality, people's perceptions of rejected alternatives can be changed with little danger of affecting their welfare. A person can dismiss all the reasons on hand for not complying, but according to this analysis, the person cannot reduce the importance of the last relevant, freely chosen behavior.

Behavioral intention; not behavior per se. But is it the person's own behavior, as observed by the self, that determines what cognitions are consonant or dissonant? Do people consider their recent behavior as "truth" and then feel motivated to eliminate or reduce knowledge that is in disagreement with that truth? This sequence of events may well occur, but not necessarily in every case. Rather, the behavioral intention should determine which other cognitions are consonant or dissonant. By "intention" we do not mean such verbal expressions as "I will try to do X" (e.g., Fishbein \& Ajzen, 1975; Ajzen, 1996), but rather, the person's felt impulse to action (see Ach, 1910). Even after having acted, and even if the person has made observable mistakes relative to the intention (see, e.g., Aronson, 1968), the 
determination of consonance or dissonance of consequences must surely be in terms of what one intended to do.

In turn, this assumption is in keeping with Festinger's (e.g., Festinger \& Canon, 1965) view of the antecedents of the perception of location. He used the term efference to indicate that the perception of location is influenced by the signals that the brain sends to the relevant musculature. If the brain signals a person's arm to reach to the right in order to touch a certain item $\mathrm{X}$, then the perception of item X's location in the visual field will tend to correspond. This efferent process is said to have precedence over the afferent-based perceptions that are not founded in behavior or readiness to behave.

It is plausible that this fundamental effect of intended behavior on cognition/perception, which Festinger and Cannon traced back to Helmholtz (1925) and von Holst (1954), was the implicit basis of cognitive dissonance theory. Though this basic insight about human behavior may well have led Festinger to formulate dissonance theory, and to his subsequent investigation of the influence of efference on perception, it is not captured in dissonance theory as formally stated (Festinger, 1957; 1964).

Research participants' perceptions of "where the commitment lies." One implication of the thinking is for a person's perception of the extremity of a value-relevant behavior. An investigator, asking a participant to "strongly" represent a certain unpopular position--such as tax increments--often assumes that the subjects who proceed to role-play do indeed enact an 
extreme sequence of actions, or at least, that the participants perceive their actions or intentions to be extreme. However, if subjects' intentions are indeed to feign a strong position, to do "as if," to withhold certain possible arguments, then they are likely enacting only a commitment that is--in their perceptions--moderately at variance from their prior value repertoire. This being the case, we should not be surprised when value/attitude change in the paradigm we have referred to is modest, not having the character of conversion.

\section{Summary}

We have outlined two quite different views of the results of role-playing or "forced compliance" procedures, neither of which agrees with dissonance theory as stated. The movement of attitudes, values, or other behavioral dispositions from a relatively strong position, to one ostensibly more moderate subsequent to induced compliance, may be the only manner in which a diverse repertoire can be reflected via simple scaling procedures. That is to say: Given that several values have been internalized, mutually at variance with one another, the result of trying to measure them with traditional scales will be a seemingly moderate position. Conversely, movement toward moderate positions can indicate that freely induced behavioral intention is the sole criterion by which cognitions can be judged as consonant or dissonant, and that the only relevant cognitions subsequent to formation of the intention are those associated with the chosen alternative. 
As will be apparent, our analyses suggest a number of directions for research. Both methodological and theoretical issues need further examination, and we hope that the present article will stimulate both thought and research concerning the fundamental assumptions of dissonance theory. 
References

Abelson, R.P. (1986). Beliefs are like possessions. Journal of the Theory of Social Behavior, 16, 223-250.

Ach, N. (1910). Ueber den Willensakt und das Temperament. Leipzig: Quelle \& Meyer.

Ainslie, G. (1986). Beyond microeconomics. Conflict among interests in a multiple self as a determinant of value. In J. Elster (Ed.), The multiple self. (pp. 133-175). Cambridge, England: Cambridge Univ. Press.

Ajzen, I. (1996). The directive influence of attitudes on behavior. In P.M. Gollwitzer \& J.A. Bargh (Eds.), The psychology of action: Linking cognition and motivation to behavior. (pp. 385-403). New York: Guilford.

Amsel, A. (1972). Behavioral habituation, counterconditioning, and a general theory of persistence. In A. H. Black \& W. F. Prokasy (Eds.), Classical condition II: Current research and theory. (pp. 409-426). New York: Appleton-Century-Crofts.

Aronson, E. (1968). Dissonance theory: Progress and problems. In R. P. Abelson, E. Aronson, W. J. McGuire, T. M. Newcomb, M. J. Rosenberg, \& P. H. Tannenbaum (Eds.), Theories of cognitive consistency: A sourcebook (pp. 5-27). Chicago: Rand McNally.

Aronson, E. (1969). The theory of cognitive dissonance: A current perspective. In L. Berkowitz, (Ed.), Advances in experimental social psychology, Vol. 4, pp. 1-34. New York: Academic Press. 
Baldwin, M.W., \& Holmes, J.G. (1987). Salience, private audiences and awareness of the self. Journal of Personality and Social Psychology, $\underline{52}$, 1087-1098.

Beauvois, J.-L., \& Joule, R.-V. (1996). A radical dissonance theory. London: Taylor \& Francis, Inc.

Berger, P. L., \& Luckmann, T. (1966). The social construction of reality. London: Penguin.

Brehm, J. W. (1956). Postdecision changes in the desirability of alternatives. Journal of Abnormal and Social Psychology, $\underline{52}, 384-389$.

Brehm, J. W. (1966). A theory of psychological reactance. New York: Academic Press.

Brehm, J. W. (1972). Some integrative effects of certain "irrational" behaviors. Annals of the New York Academy of Sciences, $193,189-193$.

Brehm, J. W., \& Cohen, A. R. (1962). Explorations in cognitive dissonance. New York: Wiley.

Brehm, J. W., \& Self, E. A. (1989). The intensity of motivation. In M. R. Rosenzweig and L. W. Porter (Eds.) Annual Review of Psychology, Vol. 40. Palo Alto: Annual Reviews, Inc.

Brehm, J. W., Wright, R., Solomon, S., Silka, L., \& Greenberg, J. (1983). Perceived difficulty, energization, and the magnitude of goal valence. Journal of Experimental Social Psychology, 19, 21-48. 
Brock, T. C. (1962). Cognitive restructuring and attitude change. Journal of Abnormal and Social Psychology, 64, pp 264-271.

Brock, T. C., \& Buss, A. H. (1962). Dissonance, aggression, and evaluation of pain. Journal of Abnormal and Social Psychology, $65,197-202$.

Charon, J.M. (1979) Symbolic interactionism. Englewood Cliffs, NJ: Prentice-Hall.

Deci, E. L. (1975). Intrinsic motivation. New York: Plenum.

Elliot, A., \& Devine, P. (1994). On the motivational significance of cognitive dissonance: Dissonance as psychological discomfort. Journal of Personality and Social Psychology, $\underline{67}, 382-394$.

Festinger, L. (1954/1999). Social communication and cognition: A very preliminary and highly tentative draft. Appendix A., pp. 355-379, in E. Harmon-Jones \& J. Mills (Eds.), $\underline{\text { Cognitive dissonance: Progress on a pivotal }}$ theory in social psychology. Washington, DC: American Psychological Association.

Festinger, L. (1957). A theory of cognitive dissonance. Stanford, CA: University Press.

Festinger, L. (1964). Conflict, decision and dissonance. Stanford, CA: Stanford University Press.

Festinger, L., \& Canon, L. K. (1965). Information about spatial location based on knowledge about efference. Psychological Review, 72, 373-384. 
Festinger, L., \& Carlsmith, J.M. (1959). Cognitive consequences of forced compliance. Journal of Personality and Social Psychology, 58, 203210.

Fishbein, M., \& Ajzen, I. (1975). Belief, attitude, intention, and behavior: An introduction to theory and research. Reading, MA: AddisonWesley.

Flanagan, G. (1996). Self expressions: Mind, morals, and the meaning of life. New York: Oxford University Press.

Fried, C. B., \& Aronson, E. (1995). Hypocrisy, misattribution, and dissonance reduction. Personality and Social Psychology Bulletin, 21, 925933.

Gergen, K. J. (1991). The saturated self: Dilemmas of identity in contemporary life. New York: Basic Books.

Goetz-Marchand, B., Goetz, J., \& Irle, M. (1974). Preference of dissonance reduction modes as a function of their order, familiarity and reversibility. European Journal of Social Psychology, 4, 201-228.

Gollwitzer, P. M. (1991). Abwaegen und Planen: Bewusstseinslagen in verschiedenen Handlungsphasen. Goettingen: Hogrefe.

Gollwitzer, P. M., Wicklund, R. A., \& Hilton, J. L. (1982). Admission of failure and symbolic self-completion: Extending Lewinian theory. Journal of Personality and Social Psychology, 43, 358-371. 
Green, D. (1974). Dissonance and self-perception analyses of "forced compliance": When two theories make competing predictions. Journal of Personality and Social Psychology, 29, 819-828.

Habermas, T. (1996). Geliebte Objekte. Berlin: Walter de Gruyter. Harmon-Jones, E. (1999). Toward an understanding of the motivation underlying dissonance effects: Is the production of aversive consequences necessary? In E. Harmon-Jones \& J. Mills (Eds.), Cognitive dissonance: progress on a pivotal theory in social psychology. (pp. 71-99). Washington, DC: American Psychological Association.

Harmon-Jones, E. (2000). A cognitive dissonance theory perspective on the role of emotion in the maintenance and change of beliefs and attitudes. In N.H. Frijda, A.S.R. Manstead, \& S. Bem (Eds.), Emotions and beliefs: How feeling influence thoughts (pp. 185-211). Cambridge, England: Cambridge University Press

Heider, F. (1958). The psychology of interpersonal relations. New York: Wiley.

Helmholtz, H. von. (1925). Treatise on physiological optics. (3rd ed.) (Ed. and translated by P. C. Southall). Vol. 3. Menasha, WI: Optical Society of America.

Hoffman, M.L. (1977). Moral internatization: Current theory and rsearch. In L. Berkowitz (Ed.), Advances in experimental social psychology, Vol. 10. New York: Academic Press. 
Horney, K. (1950). Neurosis and human growth: The struggle toward self-realization. New York: W.W. Norton.

Janis, I.L., \& King, B.T. (1954). The influence of role playing on opinion change. Journal of Abnormal and Social Psychology, 49, 211-218.

Janis, I.L., \& Mann, L. (1977). Decision-making: A psychological analysis of conflict, choice and commitment. New York: The Free Press.

Kelman, H. (1953). Attitude change as a function of response restriction. Human Relations, $\underline{6}, 185-214$.

King, B., \& Janis, I. (1956). Comparison of the effectiveness of improvised versus non-improvised role-playing in producing opinion changes. Human Relations, $\underline{9}, 177-186$.

Kvale, S. (1996). InterViews. London: Sage.

Leippe, M.R., \& Eisenstadt, D. (1999). A self-accountability model of dissonance reduction: Multiple modes on a continuum of elaboration. In E. Harmon-Jones \& J. Mills (Eds.), $\underline{\text { Cognitive dissonance: progress on a pivotal }}$ theory in social psychology. (pp. 201-232). Washington, DC: American Psychological Association.

Mead, G.H. (1934). Mind, self, and society. Chicago: University of Chicago Press.

Mills, J. (1965). The effect of certainty on exposure to infomation prior to commitment. Journal of Experimental Social Psychology, 1, 348-355. 
Mischel, W. (1996). From good intentions to willpower. In P.M.

Gollwitzer \& J.A. Bargh (Eds.), The psychology of action: Linking cognition and motivation to behavior. (pp. 197-218). New York: Guilford.

Pallak, M.S., Sogin, S.R., \& Cook, D. (1974). Dissonance and selfperception: Attitude change and belief inference for actors and observers. Unpublished manuscript, University of lowa.

Pantaleo, G. (1999). Beyond dissonance reduction? Forced compliance and the internalization of multiple perspectives. Poster presented at the 12th General Meeting of the European Association for Experimental Social Psychology, Oxford, England.

Pantaleo, G. (2001). Riduzione della dissonanza o interiorizzazione? Alcuni esempi di ricerca. In G. Pantaleo \& R.A. Wicklund, Prospettive multiple nella vita sociale: L'aprirsi e il chiudirsi degli eventi sociale. Padova/Milano: Decibel/Zanichelli.

Pantaleo, G., \& Wicklund, R. A. (2000). Multiple perspectives: Social performance beyond the single criterion. Zeitschrift fuer Sozialpsychologie, 31, 231-242.

Rosenberg, M. (1979). Conceiving the self. New York: Basic Books.

Ross, M. \& Shulman, R. F. (1973). Increasing the salience of initial attitudes: Dissonance versus self-perception theory. Journal of Personality and Social Psychology, 28, 138-144. 
Sande, G.N., Goethals, G.R., \& Radloff, C.E. (1988). Perceiving one's own traits and others': The multifaceted self. Journal of Personality and Social Psychology, $\underline{54}, 13-20$.

Shaffer, D. R., \& Hendrick, C. (1974). Dogmatism and tolerance for ambiguity as determinants of differential reactions to cognitive inconsistency. Journal of Personality and Social Psychology, 29, 601-608.

Shaver, K. G. (1975). An introduction to attribution processes. Cambridge, MA: Winthrop.

Shibutani, T. (1955). Reference groups as perspectives. American Journal of Sociology, $\underline{60}, 562-569$.

Simon, L., Greenberg, J., \& Brehm, J. (1995). Trivialization: The forgotten mode of dissonance reduction. Journal of Personality and Social Psychology, $\underline{68}, 247-260$.

Snyder, M. L., Stephan, W. G., \& Rosenfield, D. (1978). Attributional egotism. In J. H. Harvey, W. Ickes, \& R. F. Kidd (Eds.), New directions in attribution research, Vol. 2, (pp. 91-117). Hillsdale, NJ: Erlbaum.

Stearns, P. N. (1997). Fat history. New York: New York University Press.

Steele, C. M., Spencer, S. J., \& Lynch, M. (1993). Self-image resilience and dissonance: The role of affirmational resources. Journal of Personality and Social Psychology, $\underline{64}, 885-896$. 
Stone, J., Wiegand, A. W., Cooper, J., \& Aronson, E. (1997). When exemplification fails: Hypocrisy and the motive for self-integrity. Journal of Personality and Social Psychology, $\underline{72}, 54-65$.

Tesser, A. (2000). On the confluence of self-esteem maintenance mechanisms. Personality and Social Psychology Review, 4, 290-299.

Tesser, A., \& Cornell, D. P. (1991). On the confluence of selfprocesses. Journal of Experimental Social Psychology, 27, 501-526.

Tesser, A., Crepaz, N., Collins, J., Cornell, D., \& Beach, S. (2000). Confluence of self-esteem regulation mechanisms: On integrating the selfzoo. Personality and Social Psychology Bulletin, 26, 1476-1489.

von Holst, E. (1954). Relations between the central nervous system and the peripheral organs. British Journal of Animal Behavior, 2, $89-94$.

Wicklund, R.A. (1989). The appropriation of ideas. In P.B. Paulus (Ed.), Psychology of group influence, 2nd edition, (pp. 393-423). Hillsdale, NJ: Lawrence Erlbaum Associates.

Wicklund, R. A. (1999). Multiple perspectives in person perception and theorizing. Theory and Psychology, $\underline{9}$, 667-678.

Wicklund, R. A., \& Braun, O. L. (1990). Creating consistency among pairs of traits: A bridge from social psychology to trait psychology. Journal of Experimental Social Psychology, 26, 545-558.

Wicklund, R. A., \& Brehm, J. W. (1976). Perspectives on cognitive dissonance. Hillsdale, NJ: Lawrence Erlbaum Associates. 
Wicklund, R. A., \& Gollwitzer, P. G. (1981). Symbolic self-completion, attempted influence, and self-presentation. Basic and Applied Social Psychology, 2, 89-114.

Wicklund, R. A., \& Gollwitzer, P. G. (1982). Symbolic self-completion. Hillsdale, NJ: Erlbaum.

Wicklund, R. A., \& Koller, M. (1991). Psychological antecedents of consistency in applying traits. Journal of Research in Personality, $\underline{25}, 108-$ 134.

Wicklund, R. A., Reuter, T., \& Schiffmann, R. (1988). Acting on ideas: Appropriation to one's self. Basic and Applied Social Psychology, $\underline{9}, 13-31$.

Wright, R. A. (1996). Brehm's theory of motivation as a model of effort and cadiovascular response. In P.M. Gollwitzer \& J.A. Bargh (Eds.), The psychology of action: Linking cognition and motivation to behavior. (pp. 424453). New York: Guilford.

Zanna, M. P., \& Cooper, J. (1974). Dissonance and the pill: An attribution approach to studying the arousal properties of dissonance. Journal of Personality and Social Psychology, 29, 703-709.

Zanna, M. P., Lepper, M. R., \& Abelson, R. P. (1973). Attentional mechanisms in childrens' devaluation of a forbidden activity in a forcedcompliance situation. Journal of Personality and Social Psychology, $\underline{28}, 355-$ 359. 